\title{
Models for Supply Chains in E-Business
}

\author{
Jayashankar M. Swaminathan • Sridhar R. Tayur \\ Kenan-Flagler Business School, University of North Carolina, Chapel Hill, North Carolina 27599 \\ Graduate School of Industrial Administration, Carnegie Mellon University, Pittsburgh, Pennsylvania 15213
}

\begin{abstract}
Supply chain management is likely to play an important role in the digital economy. In $S$ this paper, we first describe major issues in traditional supply chain management. Next, we focus our attention on the supply chain issues of visibility, supplier relationships, distribution and pricing, customization, and real-time decision technologies that have risen to importance with the prevalence of e-business. We present an overview of relevant analytical research models that have been developed in these areas, discuss their contributions, and conclude with a discussion on future modeling opportunities in this area.

(Supply Chain Management; Electronic Business; Collaboration; Information Sharing; Decision Support; Supplier Relations; Procurement; Distribution; Customization; Literature Survey)
\end{abstract}

\section{Introduction}

It is estimated that e-commerce in the United States will grow from $\$ 72$ billion in 2002 to approximately $\$ 217$ billion by 2007, according to a recent Forrester research report (Johnson et al. 2002). While the predicted numbers may not be exact, there is no doubt that the rapid growth and adoption of the Internet has already had a great impact on all aspects of business, including customer acquisition, marketing, human resource management, finance, information systems (IS), and operations. Supply chain management that has played an important role in traditional businesses is likely to be crucial in the digital economy as well (Geoffrion and Krishnan 2001). Keenan and Ante (2002) note that during the next five years, collaboration by supply chain partners over the Internet can potentially save $\$ 223$ billion with the reduction in transaction, production, and inventory costs. This could be one of the largest benefits of Internet technology and many firms have already begun to realize these benefits. For example, Microsoft used a Web collaboration tool to bring the Xbox video game console to market two months ahead of schedule (Keenan and Ante 2002); Cutler-Hammer has doubled profits and increased productivity by $35 \%$ for its configured motor control centers and control panels by coordinating with customers over the Internet (Bylinski 2001); and Autoliv reduced the plant inventory by $37 \%$ by coordinating orders online with suppliers (Lundegaard 2001). The large potential impact of the Internet on supply chain management makes the study of supply chain models in e-business timely and important.

Supply chain management is a vast topic. We first provide a comprehensive definition of supply chain management and then discuss opportunities and changes created as a result of Internet usage.

\subsection{Supply Chain Management}

A supply chain is the set of entities involved in the design of new products and services, procuring raw materials, transforming them into semifinished and finished products, and delivering them to the end customer. This definition, or a modified version of it, has been used by several researchers (see Lee and Billington 1993, Swaminathan et al. 1998, Swaminathan 2001a, Keskinocak and Tayur 2001). Supply chain management is the efficient management of the end-to-end process, which starts with the design of the product or service and ends with the time when it has been sold, consumed, and finally, discarded by the consumer. This complete process includes product design, procurement, planning 
and forecasting, production, distribution, fulfillment, after-sales support, and end-of-life disposal. Supply chain management issues can be classified into two broad categories: configuration (design-oriented) issues that relate to the basic infrastructure on which the supply chain executes, and coordination (execution-oriented) issues that relate to the actual execution of the supply chain.

Configuration-level issues include the following topics.

Procurement and Supplier Decisions. How many and what kinds of suppliers are necessary? Which parts should be outsourced and which should be kept in house? How can procurement practices be streamlined and standardized? How should long-term and short-term contracts be used with suppliers?

Production Decisions. In a global production network, where and how many manufacturing sites should be operational? How much capacity should be installed at each of these sites? What kinds of products and services are going to be supported through the supply chain? How much variety should be provided to customers? What degree of commonality is required across the product portfolio?

Distribution Decisions. What kind of distribution channels should a firm have? How many and where should the distribution and retail outlets be located? What kinds of transportation modes and routes should be used? How should a firm exploit risk-pooling opportunities?

Information Support Decisions. Should enterprise resource planning software be standardized across the functional units of a firm? Should the supply chain work on standard protocols or on proprietary standards?

Coordination level issues include the following topics.

Material Flow Decisions. How much inventory of different product types should be stored to realize the expected service levels? Should inventory be carried in finished form or semifinished form? How often should inventory be replenished? Should a firm make inventory decisions or is it better to have the vendor manage the inventory? Should suppliers be required to deliver goods just in time?
Information Flow Decisions. In what form is information shared between different entities in the supply chain: paper, voice via telephone, electronic data interchange (EDI)? How much collaboration occurs among the supply chain partners during new product development?

Cash Flow Decisions. When do suppliers get paid for their deliveries? What prices should be charged for products? What kinds of cost reduction efforts are taken across the supply chain (or expected of suppliers)? In a global firm, in which currency will a supplier be paid?

It is clear that supply chain management spans several functional and geographical areas, introducing complexities both in terms of design and execution. Some of the pertinent factors that complicate supply chain management decisions include the presence of multiple agents and their sometimes conflicting incentives; uncertainty in demand, supply and production distribution process; asymmetry of information related to product design, inventory, costs, demand and capacity across the supply chain between the various parties in the supply chain; and lead time between the different entities in the supply chain. All these complexities lead to several types of inefficiencies in the supply chain: poor utilization of inventory assets (Lee and Billington 1992); distortion of information such as the bullwhip effect (Lee et al. 1997); high stock-outs and nonresponsive supply chains (Fisher et al. 1994); poor customer service due to customization-responsiveness challenges (Swaminathan and Tayur 1998); and double marginalization that leads to lower profits for the supply chain (Cachon 2003).

The science related to supply chain management traces its history back to the early 1950s when several researchers were interested in understanding the optimal policies related to inventory management. In one of the first works, Clark and Scarf (1960) developed models for managing inventories at multiple echelons. Numerous researchers have studied related inventory problems under stochastic and deterministic environments over the last 50 years. This stream of research (mostly from a centralized perspective) is concisely captured in the research handbook edited by Graves et al. (1993). Over the 
last decade, researchers have studied several other issues related to supply chain management that include decentralized multiagent models to analyze supply chain coordination problems, models that integrate information availability across the supply chain with logistics decisions, models for supply contracts and demand forecasting, and models that integrate product design with supply chain management. A collection of prominent research in this area is contained in Tayur et al. (1999) and Graves and de Kok (2003).

\subsection{E-Business and Supply Chain}

E-business can be loosely defined as a business process that uses the Internet or other electronic medium as a channel to complete business transactions. As classified by Geoffrion and Krishnan (2001), e-business consists of three areas: (1) consumeroriented activity and (2) business-oriented activity supported by (3) the e-business technology infrastructure. The consumer-oriented activities consist of business-to-consumer, consumer-to-consumer, and government-to-consumer activities. The businessoriented activities comprise business-to-business, business-to-government, and government-to-business activities. The technology infrastructure relates to network infrastructure, network applications, decision technologies, and software tools and applications. Within this broad definition of e-business activities, we will restrict our attention mainly to consumeroriented and business-oriented activities, as well as decision technologies that are employed for supply chain management.

The Internet has influenced the usage of supply chain models in three ways. First, the Internet has facilitated increased use of enterprise resource planning (ERP) and advanced planning and optimization solutions (APS). Second, the ability to obtain realtime information and the access to large computer systems is enabling firms to develop detailed (highgranularity) supply chain models that can be utilized to make real-time decisions. Last, the Internet has created opportunities to integrate information and decision making across different functional units, thereby creating a need for supply chain models that go beyond a business unit to study the extended enterprise. This has elevated the role of supply chain models from being decision-making enablers for a single business unit to being enablers for driving corporate strategy. Thus, the Internet has greatly elevated the role of supply chain modeling and analysis within a firm.

The advent of e-business has also created several challenges and opportunities in the supply chain environment. First and foremost, the Internet has increased the opportunity for consumers to buy products and services without going to a store. Though the practice of direct selling through catalogs and phone was in use earlier by a few firms, the Internet has made this form of sales more significant. In a direct sales environment, the fulfillment process determines how long customers will wait between sale and delivery. This has made the back-end fulfillment process-which mostly depends on supply chain management-extremely important. Further, in the electronic environment, customer expectations in terms of quick and timely delivery have also increased. At the same time, the Internet has opened up opportunities for firms to share information and efficiently coordinate their activities with other entities in the supply chain. This has created several new avenues in traditional supply chain areas. For example, in supplier selection and procurement, firms have to decide if they should join private or public exchanges or develop highly-integrated supply partnerships. They need to determine if they should use auction and bidding for contracts and, if so, which type would be most beneficial. In distribution, they need to decide if the firm will offer products through the Internet channel and, if so, how this method would differ from the traditional channel. This raises the question of how the synergies would be realized in terms of inventory, transportation, and distribution. Similarly, the availability of real-time information has raised important questions such as the degree to which information sharing protocol should be standard or proprietary; the amount and type of information that should be shared with the rest of the supply chain partners; and the types of collaborative processes that may be beneficial. The degree of change in issues related to the supply chain spans a huge spectrum from concepts and issues that 
have been marginally affected to a whole set of new issues that have emerged as a result of e-business.

First, several issues related to supply chain management have not necessarily changed in principle, although e-business may have had an impact on some of their parameters. For example, to maintain given levels of service, a firm still needs buffer inventory or buffer capacity. This has not changed as a result of the Internet, although the uncertainty involved in the decision making may have decreased with the availability of more information. Similarly, a firm still needs to take into account the interplay between fixed and variable costs, while making decisions related to procurement or setting up additional capacity. With the prevalence of the Internet, the firm might more easily be able to obtain a lower procurement price or salvage excess capacity through market mechanisms.

Next are existing supply chain issues that have become important as a result of e-business. For example, leveraging risk-pooling concepts can greatly benefit Internet channels because products may be stored at fewer locations as compared to a traditional distribution channel. Amazon.com can store all inventory for the entire U.S. market in five warehouses as opposed to several hundred retail outlets (hence, stocking points) that would be needed for similar coverage in the traditional channel. Similarly, mass customization has gained a lot of momentum with the Internet because firms can allow customers to interactively specify customizations of their offerings. It has become more important for firms to understand how to cope with customization in an effective manner.

Finally, in the last few years, a third category of issues new to supply chain management has emerged. One example is linking the dynamic pricing of products to the inventory and capacity decisions. Another is coordinating Internet and traditional distribution channels in terms of prices as well as information and product flows. Additionally, the advent of electronic marketplaces and auctions has opened a whole new set of issues related to procurement and supplier relationships.

\subsection{Focus of this Paper}

In this paper, we focus on the last two types of supply chain issues previously discussed: (1) those that have increased in importance with the Internet, and (2) those that are new issues in the e-business environment. This paper is not intended to be exhaustive in coverage, rather our aim is to concentrate on specific areas related to supply chain and e-business and highlight papers that, in our opinion, have tackled important issues. For a more exhaustive coverage, the reader is referred to the research handbook by SimchiLevi et al. (2003). In particular, our focus will be on papers that utilize analytical modeling and operations research methodology in supply chain planning and execution. This is a relatively new area, thus, many of the research papers discussed in this article are unpublished.

1.3.1. Procurement and Supplier Management. The e-business paradigm has created an immense opportunity for firms to consolidate their buying processes (also called e-procurement). The first success stories in the area of e-procurement came from software firms Ariba (http://www.ariba.com) and Commerce One (http://www.commerceone.com), which primarily dealt with indirect goods and services. The initial idea in these systems was that when procurement is consolidated under a single roof, the firm benefits from price reductions (a direct result of quantity discount). E-procurement systems enable individual employees to become aware of all qualified suppliers and to complete the procurement process quickly and easily. Subsequently, more advanced models for procurement have evolved that use auctions to determine which firm wins a procurement contract. Each contract is open to bids in an electronic auction house and qualified suppliers are allowed to participate. Although auctions have been used for industrial contracts before, execution was rather cumbersome and, thus, were used only for large and important contracts. E-business firms such as FreeMarkets (http://www.freemarkets.com, a business-to-business, third-party auctions firm) have made it much easier to conduct these auctions and, as a result, firms are beginning to use these auctions more frequently for procurement. This poses new research issues such as whether a firm should use such auctions for all its components and suppliers; what the long-term effect of such auctions on supplier relationship is; how firms can use both traditional 
and auction mechanisms to hedge against risks in a more efficient manner; and how a third party such as FreeMarkets can ensure that capacities of suppliers are taken into account in these auctions so that the contract is executable.

A related phenomenon in the supplier management area is the formation of industry-wide supply chain consortia such as e2open (high tech) and Covisint (automobile). The motivation behind the formation of these consortia (also sometimes called marketplaces) is their ability to provide liquidity to inventory and capacity present in the extended supply chain and make it possible for the supply chain partners to get involved in long-term collaborative planning and design efforts. For example, a manufacturer with excess inventory could salvage it in the marketplace. Similarly, buyers may have the ability to conduct auctions for industrial parts and procure capacity options from the supply base. There are a number of new research issues that have evolved as a result of the above changes. For example, how could one quantify the benefits of joining such a consortium for a firm; how many firms of the same type are likely to stay in a consortium; how could the different firms use the liquidity and options in the marketplace to improve their operational performance. We will discuss research on the issues of procurement and supplier management in $\$ 2$.

1.3.2. Visibility and Information Sharing. The prevalence of ERP allows firms to have access to data across their supply chains, which could be used for gaining better efficiency and effectiveness (Sodhi 2001). The ability to access information from various parts of the organization has helped firms to streamline their business processes and reduce inefficiencies. Although ERP systems were implemented before the boom in e-business, their potential could not be explored and expanded due to lack of common standards and cost of access. The growth of e-business allows and requires that the information made available from the ERP systems be shared with other firms in the extended supply chain through the Internet. This enables firms to coordinate and collaborate with their suppliers and customers as well as synchronize their in-house operations.
The ability to access information across the supply chain and use it in real time provides various opportunities. Inventory requirements for buffer stocks are likely to be lower, because the uncertainty in forecasts and demand can be reduced across the supply chain. Allocation of inventory to different retail outlets or customers as part of order fulfillment can be done more effectively when there is visibility about the number and type of inventory located at the different sites in the supply chain. As more supply chain execution information becomes available, firms can plan for future operations using advanced planning and optimization tools. The ability to share information creates an opportunity for firms to have collaborative planning and design, which removes the inefficiencies in these processes. This has opened up several new issues for researchers. For example, if forecasts are shared more often than before, how should they be used more effectively; how can collaborative forecasts be generated and used across the channel; how can a firm use the demand, inventory, or supply information from other partners more effectively. We will discuss research on these issues in $\S 3$.

1.3.3. Pricing and Distribution. Physical retail stores have traditionally been the most common mode of distribution. Catalog firms have traditionally been considered a rather niche market for only certain types of products. E-business has opened up a completely new dimension to distribution by enabling firms to use alternative distribution channels in addition to brick-and-mortar stores. Also, the ability to share information across the supply chain has made it easier for firms to try to coordinate the flow of materials across multiple channels. In a rush to exploit this opportunity, several firms during the last few years have set up Internet stores and created new businesses (such as online grocery). However, many of them paid little or no attention to logistics associated with those operations and, as a result, did not go far. For example, online grocers grossly underestimated the transportation costs associated with the "last mile" delivery and the effect of capacity utilization on economies of scale (Reinhardt 2001). Traditional firms such as IBM, Barnes \& Noble, and Wal-Mart also faced challenging issues during this period when they created their own Internet operations. These questions 
included how the Internet operation should differ from traditional practice; how the products should be priced across these two channels; whether all products should be offered on both channels; and what kind of autonomy should be provided to Internet operations.

The ability to dynamically change prices in the marketplace is yet another aspect of distribution that e-business has greatly impacted. In traditional supply chain operations, price changes were allowed but would occur only at regular or planned intervals. However, the Internet enables firms to more dynamically adjust prices with little additional effort. This poses interesting issues related to how often prices should be changed and how one can effectively couple dynamic pricing with production or capacity decisions.

The Internet has compounded one of the benefits of distribution that relates to risk pooling. Because products may be stored at fewer physical locations, the benefits of risk pooling will lead to lower inventory requirements. Having a separate inventory depot for Internet operations provides the ability to adjust inventory allocations between the retailer and the inventory depot. This raises several important research issues. How much inventory should be stored at the various locations? How can firms create incentives so that the brick-and-mortar retailers can collaborate with each other? We discuss pertinent research related to distribution and pricing in $\S 4$.

1.3.4. Customization and Postponement. The Internet has increased the expectation of customers for complete customization at a nominal charge. Even before the advent of e-business, firms faced the challenges related to mass customization and high product variety, but this has increased immensely over the last few years. Part of the reason is the Internet provides an easy and convenient way for customers to express their preferences, and sometimes even view the product as it is customized. Firms are finding that it is important not to completely rely on traditional manufacturing paradigms of inventory building (make to stock). They are fine tuning their production process so that they can store inventory of raw materials or semifinished inventory and more rapidly respond to customer demand after the customer has ordered the product. We will discuss several models that capture the trade-offs in these operations and their effect on supply chain performance in $\$ 5$.

1.3.5. Enterprise Software and Decision Support Technologies. Last, the Internet has had a great impact on development of decision technologies that use the available data across the supply chain. In the past, although the models were available, their implementation in real time was almost infeasible. As a result, they were mainly used for planning purposes. However, the Internet has facilitated real-time access to information across the supply chain, making it now possible to use decision models during execution. A related phenomenon is the development of intelligent supply chain software agents that could take appropriate actions in real time, thus, streamlining supply chain operations. In $\S 6$, we discuss some of these decision technologies in greater detail.

\section{Procurement and Supplier Selection}

One of the major effects of the Internet on supply chain practices is in the area of procurement. Firms now use the Internet, not only to diversify the supply base and hedge risk, but also to obtain lower costs through auctions. This has raised important issues related to supply chain management. At the strategic level, firms need to decide whether they should have long-term contracts with a few fixed suppliers or use auctions and a dynamic supplier base to reduce their costs. In particular, firms need to understand under what circumstances is it beneficial to have (1) longterm relationships; (2) auction-based, short-term relationships; or (3) a combination of (1) and (2). Another important decision is whether a firm should have one supplier or multiple suppliers and how that choice may depend on repetition in purchase. Elmaghraby (2000) presents an extensive survey of economicsoriented models that deals with supplier selection and sourcing strategies in traditional settings. Our focus will be on supplier selection and procurement models under uncertainty in demand or supply that incorporate the ability of the firm to use the Internet to make the process more efficient. 
Peleg et al. (2002) develop a model that considers the potential discounts that an exclusive long-term supplier may be able to offer based on learning and compare that to the savings that might be generated through an auction, in a two-period setting with uncertain demand. The strategic partner guarantees a price of $p$ per unit in the first period and $p(1-\Delta)$ in the second period, where $0<\Delta<1$. This model attributes it to the long-term learning effects of an exclusive supplier. In an auction-based setting, the firm still pays a per unit price $p$ in the first period, but conducts an auction in the second period. The firm only knows the distribution of the minimum price (which is assumed to be independent of the quantity bought) that could be obtained as a result of the auction. In the combined strategy, the firm decides to use the exclusive supplier for the most part (by having a contract to order a minimum amount in the second period) and orders any remaining amount from the auction. Under random demand assumptions, Peleg et al. (2002) derive the optimal ordering quantities for the firm. They show that there exists a $\Delta$ beyond which it is optimal for the buyer to prefer a strategic long-term partnership, as opposed to using an auction in the second period. Further, depending on the distribution of price obtained from the auction, the combined strategy may be superior or inferior to a pure auction strategy. Finally, the authors explore the effect of increasing the supplier base (in the auction) by modeling the benefits obtained (due to potential lower prices) in the distribution of price from the auction.

In the automotive supply chain, a tier- 1 manufacturer such as Ingersoll-Rand often has to reserve capacity from its supplier, worldwidepm.com, which is a coalition of small powder metal technology manufacturers. Because the coalition is a powerful entity, the manufacturer may need to develop contracting mechanisms such as capacity reservation (which is similar in spirit to the minimum order assumptions of Peleg et al. 2002). Motivated by the above setting, Erhun et al. (2001) study the strategic interaction and questions of participation (from the suppliers), profit sharing, and impact on end customers. They analyze a two-period model where the downward sloping demand in the second period could be in one of two states. This uncertainty is resolved in the second period where demand becomes deterministic. In contrast to standard two-period models, they assume that demand only occurs in the second period. The first period is only for capacity reservation and demand resolution. Under this setting, they demonstrate the existence of a unique subgame perfect Nash equilibrium under the various models. They show that the supplier, manufacturer, and the supply chain as a whole are aided by this additional negotiation period where demand is actually not realized, but demand resolution occurs and capacity is reserved. Under uncertain demand and limited capacity at the supplier, they show that the additional period is beneficial, but the impact on profits (and its sharing) is more involved and depends on the level of capacity available.

As more and more firms begin to use auctions for conducting business transactions, it is important that models be developed that capture the buyer bidder interactions and tie them to supply chain decisions and constraints. Motivated by FreeMarkets, Gallien and Wein (2000) study the design of smart markets for industrial procurement. They study a multi-item procurement auction mechanism for supply environments with capacity constraints. This enables them to model rational behavior of suppliers in terms of their responses when they have limited capacity. In particular, they consider an auction with $n$ suppliers and $m$ components, each having a fixed order size. The objective of the manufacturing firm is to minimize the total cost of procurement across all the components, taking into account the capacities of the various suppliers. In each round, suppliers give a price bid for each of the components. The assumption is that the price bids decrease as the rounds progress. Further, at the end of each round, the auctioneer provides each of the suppliers information about allocations and the best bids for the next round that would maximize the supplier's profits, assuming all other suppliers hold on to their old bid. The auction stops when the new set of bids from all the suppliers is identical to the previous round. Under these conditions, the authors show that such an auction does converge, and they provide a bound for the profits of the manufacturer. 
Further, for special cases with two suppliers, they provide insights on the impact of initial bids.

Davenport and Kalagnanam (2001) study auction strategies for sourcing large quantities of direct materials over the Internet. They study two auction mechanisms, the first of which solicits supply curves as bids to capture quantity discounts. The second auction aggregates short-term demand across multiple manufacturing facilities and allows suppliers to provide bundled all-or-nothing bids. They incorporate business rules as side constraints in their integer programming formulation and use computational results to study these mechanisms.

While an auction typically serves as a pricedetermination mechanism, Jin and $\mathrm{Wu}$ (2001a) show that the auction could also serve as a coordination mechanism for the supply chain. They demonstrate that different forms of auction and market mechanisms change the nature of supplier competition, thus, the buyer-supplier interaction. In particular, they consider a two-supplier-one-buyer system under four different types of market schemes. They propose a two-part contract auction where the buyer announces a price-sensitive order function, while the suppliers compete in an ascending bid side-payment auction. Channel coordination can be achieved if the market intermediary strives to reduce the extent of information asymmetry, while restricting the buyer's profit on the side payments. Using the insights from the two-supplier-one-buyer analysis, they rank market schemes by their impact on expected channel efficiency, expected profitability for the buyer, expected profitability for the winning supplier, and expected commission revenue for the market maker.

Lee and Whang (2002) investigate the impact of a secondary market where resellers can buy and sell excess inventories. They develop a two-period model with a single manufacturer and many resellers. The resellers order products from the manufacturer in the first period and are allowed to trade inventories among themselves in the second period. They derive the optimal decisions for the resellers, along with the equilibrium market price of the secondary market. Two types of effects are created due to the secondary market: (1) a quantity effect (sales by the manufacturer), and (2) an allocation effect (supply chain performance). They show that the former is indeterminate, i.e., the total sales volume for the manufacturer may increase or decrease, depending on the critical fractile. However, the latter is always positive, i.e., the secondary market always improves allocation efficiency. The sum of the effects is also unclear in that the welfare of the supply chain may or may not increase as a result of the secondary market. Finally, the authors present potential strategies for the manufacturer to increase sales in the presence of the secondary market. Dong and Durbin (2001) study other implications of such surplus markets on supply chain efficiency. Keskinocak and Tayur (2001) describe examples where matching algorithms developed by operations researchers have been used in marketplaces as decision support for matching demand and supply. Kleindorfer and $\mathrm{Wu}(2003)$ present a detailed analysis of research related to integrating long-term and short-term contracting using B2B exchanges.

A related phenomenon in the area of procurement and supplier relationships has been industry-wide consortia where multiple buyers and suppliers within an industry join and conduct business. Better transactional efficiency has been highlighted as the key benefit of consortia such as Covisint (automotive) and Converge (high tech). The dynamics of these entities are not well understood and pose several important questions. For example, one could expect that having multiple suppliers on the same platform is likely to reduce prices for the buyer, but it is likely to benefit other buyers in the consortium as well. Thus, it is not clear if one should join the consortium in the first place. One of the reasons for Dell deciding not to join either of the high-tech consortia, Converge or e2open, could be that they do not want to open up their supply chain processes to competitors. Granot and Sosic (2001) study this issue using a stylized model where there are three firms whose products have a certain degree of substitutability. They explore conditions under which formation of three-member and two-member alliances is optimal. In particular, they consider a deterministic linear model for the demand that depends on the prices charged by the firm and its competitors, and the degree of substitutability across the products. They assume that when alliances are formed, the procurement cost (or the price paid by 
the firm) strictly decreases, and that the sum of the reductions due to a firm joining a two-firm coalition with each of the other firms is greater than the reduction obtained when all three firms are in the alliance. With these decreases in costs, the authors derive conditions under which joining a three- or two-party coalition is beneficial for a firm. They also identify conditions under which a firm may prefer to be in a two-firm alliance to prevent others from forming an independent two-firm alliance even though this may lead to lower profits. The authors also provide several other insights into the stability of these alliances.

Jin and $\mathrm{Wu}(2001 \mathrm{~b})$ study the formation of supplier coalitions in the context of a buyer-centric procurement market. They consider a second-price descending sealed-bid auction and propose a two-stage auction mechanism that allows suppliers to form coalitions with one another. Building on the foundations of core games and bidding rings, they explore the idea of managed collusion, which provides a means to enhancing bidder profitability. They also identify basic requirements for a valid coalition mechanism, including characteristics such as individual rationality, welfare compatibility, maintaining competition, and financial balance. They show that such a mechanism could be constructed so that the buyer does not lose the advantage from supplier competition, and a stable coalition structure could be formed. They propose a profit distribution scheme among members in the supplier coalition and show that the proposed scheme provides proper incentives such that (1) the best strategy for a coalition member is to comply with the coalition agreement, and (2) bidding the true cost is the best strategy so long as the bids are uniformly distributed and the bidder's cost is above a certain threshold. They also investigate the stable coalition structure under the proposed mechanism, and show that under symmetric information there exists one unique strongly stable coalition structure.

Butler et al. (1997) suggest that the prevalence of the Internet will lead to a reduction in costs of interaction among firms that may make horizontal alliances (i.e., alliances between similar businesses) more attractive. Nault and Tyagi (2001) examine coordination mechanisms that achieve an alignment between the success of the alliance and its individual members. They consider coordination mechanisms for a horizontal alliance characterized by the following features: (1) firms in the alliance can exert effort only in their local markets to increase customer demand for the alliance, (2) customers are mobile, and a customer living in a given alliance member's local area may have a need to buy from some other alliance member, and (3) the coordination rules followed by the alliance determine which firms from a large pool of potential member firms join the alliance, and how much effort each firm joining the alliance exerts in its local market. In this horizontal alliance setup, they consider the use of two coordination mechanisms: (1) a linear transfer of fees between members if demand from one member's local customer is served by another member, and (2) ownership of an equal share of the alliance profits generated from a royalty on each member's sales. The authors derive conditions on the distribution of demand externality among alliance members to determine when each coordination mechanism should be used separately, and when the mechanisms should be used together.

\section{Visibility and Information Sharing}

The Internet has made it easier to share information among supply chain partners. The current trend in the industry is to try to leverage the benefits obtained through information sharing (also called visibility) across the supply chain to improve operational performance, customer service, and solution development. The notion of lack of information in the supply chain and the resulting bullwhip effect was first studied by Lee et al. (1997). Chen et al. (2000) quantify the effect of forecasting and lead times on the bullwhip effect under stylized supply chain settings. A number of other papers have dealt with the flow of information in the supply chain and the effect of that on its performance. We will only focus on a few papers in the interest of space.

Gavirneni et al. (1999) consider the role of information in a two-stage capacitated supply chain under three types of information flow: (1) no information is shared with the supplier (2) the supplier knows the end-item demand distribution and the retailer uses 
an $(s, S)$ policy, and (3) the supplier has complete information about the inventory state of the retailer. The authors show the optimality of order-up-to policies for finite and infinite horizon models. Through a computational analysis, they study the role of information availability and the savings obtained under different operational conditions. Lee et al. (2000) study the value of information in a two-level supply chain with nonstationary end demand and show that value of information could be high, particularly in cases where demand may be correlated over time. The effect of vendor managed inventory (VMI) systems, where the buyer shares demand information with the supplier who, in turn, manages the buyer's inventory, have also been extensively studied by researchers (see Cetinkaya and Lee 2000 and Cheung and Lee 2002).

A related issue in supply chain information sharing is sharing forecast information. It is highlighted in the popular press that one of the reasons for Dell's success is its ability to transmit timely and accurate forecasts to its suppliers. Because forecasts are not always accurate, firms may pass demand information in the form of bands (lower and upper estimates) that may get more refined as one gets closer to the actual period of ordering. It is important to understand how frequent forecasts can be used to improve supply chain performance. Kaminsky and Swaminathan (2001) present a model for forecast evolution that captures two notions related to forecasts: (1) forecasts are not exact and (2) forecasts over longer horizons are less certain than those over shorter horizons. With this forecast evolution model, they develop a capacitated production planning model for a single product with terminal demand. After showing that the optimal production policy is order up to, they develop heuristics for the problem and characterize their performance. Through a detailed computational study, the authors show that these heuristics get close to the optimal solution with holding costs (less than $0.5 \%$ away from optimal on average under the conditions studied) and provide insights on the effect of early, intermediate, and late information updates in forecasts on optimal costs. Although it is reasonable to assume that forecasts do get better as one gets closer to the decision epoch in most cases, Cattani and Hausman
(2000) demonstrate situations when forecast updates may not get better over time. Miyoaka and Hausman (2001) study a two-stage supply chain where using old forecasts may be better.

Although sharing forecasts can be beneficial in most cases, and the Internet does facilitate the sharing of such information, conflicting objectives may cause the forecasts to be distorted. Celikbas et al. (1999) address this issue in a intrafirm setting where marketing and manufacturing units may have conflicting objectives regarding forecasts. Marketing, being a revenue center, may have an incentive to overforecast whereas manufacturing, being a cost center, may have an incentive to underproduce as compared to the forecast. The authors study a decentralized setting where demand is uncertain and marketing provides a forecast to manufacturing, which in turn produces a quantity based on the forecasted amount and the knowledge about the demand distribution. They show that by suitably setting penalties for overforecast and underproduction, one can coordinate the system. Chen (1999) considers a supply chain whose members are divisions of the same firm and are managed by different individuals who have local inventory information. He shows that the owner of the firm can manage the divisions as cost centers without compromising the systemwide performance by using an incentive-compatible measurement scheme based on accounting inventory levels. Similar to Celikbas et al. (1999), Chen (1999) shows that it is important for the upstream members of the supply chain to have access to accurate customer demand information. More recently, Cachon and Lariviere (2001) study forecast sharing in a two-stage supply chain between a manufacturer and a supplier, where the manufacturer provides an initial forecast and a contract to the supplier, who in turn invests to set up capacity in anticipation of demand. The focus of the study is on two types of compliances: (1) forced compliance, where the supplier is forced to develop a given capacity once he accepts a contract from the manufacturer and (2) voluntary compliance, where the supplier can set the capacity optimally. Cachon and Lariviere (2001) show that compliance regime plays an important role in the supply chain performance. The authors find that it is always in the interest of 
the manufacturer to truthfully share the forecast with the supplier, particularly when the demand forecast is high.

A growing movement in the industry is collaborative planning, forecasting, and replenishment (CPFR), which tries to reduce the differences that may exist between the different supply chain players (retailer, distributor, manufacturer) regarding demand forecast for a product. In CPFR, the two parties (typically manufacturer and retailer) jointly collaborate to generate a forecast and plan for that forecast. Such a forecast, which uses the information available to all supply chain players, is likely to make the supply chain operations more efficient because: (1) the forecast is coordinated, and (2) the forecast carries richer information. Aviv (2001) studies a two-stage twoplayer cooperative supply chain. He assumes that the supply chain is decentralized so that information such as inventory position and individual forecasts are only locally available. Under collaborative forecasting, Aviv (2001) assumes that both the manufacturer and retailer maintain and use a single forecast process for production replenishment. He compares the benefits of collaborative forecasting and local forecasting in a setting with stationary demand distribution.

\section{Distribution and Pricing}

Traditional research in the area of distribution has mainly focused on three issues: (1) the optimal location of distribution centers and warehouses, (2) inventory and allocation in a distribution network, and (3) transportation and routing algorithms. Such models have been studied by researchers in operations research (OR) for several years. For example, Geoffrion and Graves (1974) study the multicommodity warehouse location problem for a major food firm; Eppen and Schrage (1981) study the inventory allocation decisions in a distribution network; and Bramel and Simchi-Levi (1997) present an overview of logistics research. During these years, OR researchers have developed effective solution methodologies for solving large-scale instances of the production distribution problem that have enabled firms to streamline their supply chains. Arntzen et al. (1995) describe the implementation of such a model for reengineering at DEC.
The Internet has provided another channel for distribution of goods. With the prevalence of businessto-consumer and business-to-business e-commerce, several firms such as Amazon have had to develop a comprehensive distribution network for their business. Clearly, the customer base is more dispersed and in many cases, customers may buy goods that need to be delivered elsewhere (such as a gift). Neglecting the costs and synergies related to distribution and transportation have proved fatal to several early movers in this business. In particular, firms that have been most affected by this were online grocers (like Peapod and Webvan) and home delivery firms (like Kozmo and HomeRuns). This primarily occurred because these firms had to deal with numerous tight delivery time windows (mostly customer preferred) in addition to other logistic complexities, which made it extremely difficult to gain efficiency through synergies in distribution and transportation.

From a supply chain standpoint, the integration of traditional and Internet distribution channels is attractive because it promises profit gains, inventory reduction, and increased customer service. However, many of the traditional channels are not necessarily centrally controlled. Seifert et al. (2001) study inventory coordination contracts and their impact on the direct and indirect channels. Motivated by an actual business line at Hewlett Packard, they consider a situation where the firm has $N$ traditional identical retailers and one virtual store and random demand. The assumption is that when a customer is unable to get the product at the virtual store, then she is willing to wait. If there is excess inventory at the retailer outlet at the end of the period, then it is used to satisfy the demand. Retailers individually make the inventory decisions in a decentralized system, whereas the manufacturer makes decisions related to inventory at the virtual store. When the channels are not integrated, then a menu of buy-back contracts can coordinate the system. In an integrated supply chain (where excess inventory from the traditional channel is used to satisfy excess demand from the virtual store), Seifert et al. (2001) show that when a transfer payment scheme is introduced in addition to a buy-back scheme, the decentralized system can be coordinated. Through a detailed computational study, 
they provide several managerial insights into profits and inventory as a function of number of retailers and degree of coordination.

Anupindi and Bassok (1999) consider a model with two retailers and one manufacturer, and explore the benefits to the manufacturer and the channel if the two retailers centralized their inventory in a lost sales setting. Their study was motivated by some early pilots by General Motors where the firm was exploring how demand and supply availability information in the distribution channel could be more beneficially used. The authors find that centralization of stock by the retailers need not be in the best interest of the manufacturer. The true benefits to the manufacturer may depend on the service levels of the retailers and the degree of substitution (which they term "search") of demand between the two retailers. The authors prove that there exists a threshold level of search beyond which it is detrimental to manufacturer's profits if the retailers centralize their inventories when the wholesale price is fixed. For high search parameters, even the supply chain profits may decrease as a result of centralization. Even under an optimal wholesale price setting, they show that a manufacturer may be better off with a decentralized system when the degree of search is high.

Netessine and Rudi (2001) study incentive issues related to drop shipping in business-to-consumer supply chains. In the drop-shipping method (commonly used by many e-tailers) the retailer is primarily concerned with customer acquisition (as a result, does not store any inventory) and the wholesaler takes inventory risk and performs fulfillment. They analyze three different drop-shipping methods in a multiperiod setting with different power structures: powerful retailer, powerful wholesaler, and both equally powerful. These power structures determine the sequence of actions taken by the firms and whether the resulting equilibrium is Nash or based on Stackelberg. In particular, they assume that demand is stochastic and the demand distribution is a linear combination of a random component and a function of effort expended by the retailer for customer acquisition. Netessine and Rudi (2001) also assume that the mean demand is increasing and concave in the customer acquisition spending. They obtain optimal solutions for the centralized system and traditional (where the retailer decides both customer acquisition effort and quantities) and drop-shipping (where the retailer decides on the effort and the wholesaler decides on the quantity) methods, and show that these decentralized systems are not as efficient. Further, Netessine and Rudi (2001) show that traditional contracts based on buy-back or quantity discounts cannot coordinate the above decentralized systems. They show that a contract that also includes a compensation for the retailer's marketing expense can coordinate the system. Finally, several numerical insights on the problem are provided.

Anupindi et al. (2001) develop a general framework for modeling various issues in decentralized distribution channels such as drop shipping, fulfillment houses, and inventory speculators. They consider $N$ retailers who face stochastic demand and hold stocks locally and/or at one or more central warehouses. They assume a given level of substitutability, so if a retailer is stocked out, a certain portion of that demand can be satisfied from existing inventory at other retailers or the central warehouses. The main decision relates to planning for inventory and allocation. In a "coopetitive" framework, they develop the notion of a claim that establishes ownership rights for each unit of inventory in the system regardless of its location. Thus, by buying a claim on a unit, a player gets the right to determine how the unit will be used once demand is realized. This enables analysis of the inventory decision as a noncooperative game. Simultaneously, the authors assume that the shipping and allocation decisions are cooperatively made. Using the concept of a core (an allocation scheme, which makes sure that coalitions are stable), they develop sufficient conditions for the existence of one. They also develop conditions for the existence of a Nash equilibrium for the inventory decisions. Under the above conditions, they show the existence of an allocation mechanism that leads to a coordination across the supply chain and develop conditions for its uniqueness.

Cattani and Souza (2002) study a model where an Internet distributor determines the inventory to stock given that there may be alternative categories of customers (who may differ in delivery requirements) and that there may be alternative ways to ship the 
product. In particular, they assume that there are two types of customers: (1) those who want air shipment and (2) those who want ground shipment. Using a queuing model with Poisson arrivals and exponential service times, they analyze five different allocation policies. These range from simple ones such as first-in, first-out (FIFO) to more profound policies that take into account the inventory position and prioritize the customer types accordingly. One such policy serves both types of customers until inventory drops below a threshold $S^{*}$, beyond which only the air shipments are completed (while the ground orders may be backlogged or lost). Once the inventory level increases beyond the threshold (assuming the machine is always running), the backlogged demand is upgraded to an air shipment. Using a computational study, they provide insights into the usefulness of such flexibility.

In traditional supply chain research, pricing has not been an issue because models have been developed for a single entity whose demand is exogenously prescribed (of late, there are models for competition being analyzed; see Cachon 2003). However, with the advent of the Internet, even a single firm needs to decide how to differentially price products over the traditional and the Internet channels. Brynjolfsson and Smith (2000), in their empirical study of book and CD prices over a 15-month period, concluded that the Internet prices are $9 \%-16 \%$ lower than prices in conventional outlets. Further, how firms price their products on the traditional and the Internet channels may depend, to a great extent, on the firm's strategy and the degree of autonomy provided to the Internet arm of the firm. For example, some firms see the Internet as a medium of convenience for customers trying, instead, to provide useful information on their products, but few discounts. On the other hand, several firms (like Wal-Mart) spun off their Internet arms as independent entities and gave them complete freedom to operate their own way.

Cattani et al. (2002b) study optimal pricing for a firm that sells on both traditional and Internet channels, given that the cost and customer preferences in each segment could differ. In particular, they consider a linear customer utility model where each customer has an independent preference for the Internet and traditional channels. The customer's choice of channel depends on the prices of both channels and the customer's individual preference. Under the assumption of uniformly distributed customer preferences, Cattani et al. (2002b) analyze the impact of various pricing and governance issues under monopoly and competition. Under monopoly, they consider four different pricing schemes: (1) where traditional channel prices are not changed and the Internet channel optimizes its own profits, (2) where traditional channel prices are unchanged but the Internet channel prices are set to optimize the joint profit, (3) where both channels price identically but the optimal price is chosen, and (4) where both prices are jointly optimized. Cattani et al. (2002b) show that optimal prices depend, to a great extent, on customer preferences and cost of the two channels. Further, they establish threshold levels in the difference between the traditional and Internet costs, beyond which it is optimal to price one channel higher than the other. In the competitive case, they consider a traditional monopolist who is competing against a pure e-tailer. Cattani et al. (2002b) show the existence of a unique Nash equilibrium. With a detailed computational study, the authors provide interesting insights that, under many conditions, a firm, in fact, could be close to optimal under case (2) above where they do not change the traditional channel but align the Internet channel with the existing business. Also, the joint pricing strategy in case (3) is reasonable when the costs are not different across the two channels. Finally, Cattani et al. (2002b) show that case (1), a strategy adopted by many firms over the last couple of years, could be quite detrimental to the firm's profits. Using a stylized linear downward sloping demand function, Huang and Swaminathan (2003) analytically prove that profits under cases (2) and (3) are no more than $4 \%$ away from the optimal. Further, they show that under competition, a retailer that has both the Internet and traditional channels, will price products higher than a pure Internet retailer.

Druehl and Porteus (2001) examine price competition between two firms, one that has an Internet channel and another with a brick-and-mortar channel, under similar demand assumptions as above. Additionally, they assume that only a fraction of the 
population has access to the Internet and is willing to buy online. They solve for the firm's optimal prices in Nash and Stackelberg games and relate the competitive outcomes (market structure) in terms of the degree of innovation. The degree of innovation is effectively a maximum possible margin (maximum reservation price minus unit cost) ratio for the two firms. As the fraction of consumers willing to buy online increases, they find that the duopoly outcome becomes more likely. Thus, even when almost everyone is willing to buy online, both firms are likely to make positive profits. Using the degree of innovation, they discuss the importance of marketing and cost control. Balasubramanian (1999) studies a related problem where he analyzes the competition between a direct channel and traditional retailers. He models the customer space in the form of a circle where the customers are uniformly distributed around the circumference. The direct channel is located at the center of the circle equidistant from all the customers, thereby having a single location or preference parameter that determines both the traditional and direct channel distance for a customer (because the distance from the center is fixed at the radius of the circle). Given this model of the customer space, Balasubramanian (1999) derives the competitive equilibrium prices between traditional and direct channel, and explores the impact of information related to availability of the product from the direct channel to customers.

Another related issue is dynamic pricing. With the advent of the Internet and greater connectivity, firms have a greater ability to dynamically price their products. This approach has been successfully adopted by firms in the airline, hotel, and rental car businesses where the product or service has a perishable nature. Auctions and bidding are also sometimes referred to as dynamic pricing models, and have become prevalent in an e-business environment as discussed in §3. Another related dynamic pricing model relates to pricing products based on supply chain characteristics such as offloading excess capacity. The key issue is the integration of production and pricing decisions through the supply chain. Motivated by an initiative at General Motors, Chan et al. (2001) study a model that develops dynamic prices, which are integrated with the production and inventory control for nonperishable products in a multiperiod setting. Chan et al. (2001) allow for periodically varying demand, holding costs, capacities, and production costs. In particular, they consider a model where demand is assumed to be a nonincreasing deterministic function of price and the revenue function is assumed to be concave. Further, they restrict both production and inventory to be integral values and have upper and lower bounds on the price the firm can charge in each period. With these assumptions, they show that the constraint matrix is a polymatroid and prove that a greedy allocation algorithm for production is optimal. Using an extensive computational study, they offer various interesting insights into the benefits obtained from dynamic pricing under different operational conditions related to capacity, demand, and frequency of price changes.

\section{Customization and Postponement}

Traditional inventory management models assume that inventory is stocked and demand is satisfied based on availability (called make-to-stock systems). Swaminathan and Tayur (2003) provide an extensive review of research advances in this area. For most consumer products, the make-to-stock system was an appropriate business model. However, the Internet has resulted in a growing movement toward selling directly to customers, which has increased the degree of customization. For manufactured products, firms have moved to a build-to-order environment or have adopted postponement (also called delayed differentiation). Venkatesh and Swaminathan (2003) describe successful implementations related to postponement across industries and discuss costs and benefits associated with alternative types of postponement. Swaminathan (2001b) describes examples that illustrate the increase in customization due to the Internet. For example, ewatchfactory (http://www.ewatchfactory.com) enables a customer to completely customize a watch. This business model depends on the Internet and a postponement strategy at the final assembly. Another firm, Timbuk2 
(http://www.timbuk2.com), allows consumers to customize their computer bags, messenger bags, and laptop sleeves. Again, such a business opportunity could be exploited due to the Internet and a clever combination of make-to-order and make-to-stock strategies. In the next few passages, we highlight a handful of papers that deal with postponement and customization models. For a detailed overview on postponement models, see Swaminathan and Lee (2003).

Lee (1996) describes the most basic version of the delayed differentiation model where there are $M$ products and inventory is carried in finished form. All products are customized from the inventory available at the end of the standard steps of the process. This model is similar to the one-warehouse multiretailer inventory problem studied by Eppen and Schrage (1981). The basic assumption is that the standard part of the process takes $t$ time periods to complete, and the remaining $T-t$ periods correspond to time for the customization step. This is analogous to the warehouse lead time of $t$ periods and $T-t$ periods of transportation time from the warehouse to the retailers. All the products are assumed to have independent and normal demands with mean $\mu_{i}$ per period and standard deviation $\sigma_{i}$ per period. Lee (1996) analyzes this system with process standardization and addresses the impact of postponement, which is reflected in the parameter $t$. He shows that the variance of the inventory is decreasing in $t$. Thus, postponement will lead to reduction of inventory of finished products. Further, the reduction in inventory is greater when the end product demands are negatively correlated. Lee (1996) also shows that the reduction in variance is greater when the number of identical end products is larger. Lee and Whang (1998) further explore this model by assuming that demands are not independent and identically distributed (IID) over time. With non-IID demand, the value of postponement is more than just the ability to make product commitments at a later point in time when realized demands have been revealed. The progression of demands may also help to improve the forecast of the future demands.

The above models share an implicit assumption that the production-distribution process is continuous, and inventory can be stored only in finished products form. In general, manufacturing environments involve a discrete set of operations, and inventory can be stored immediately following any one of these stages. Furthermore, the costs associated with delaying differentiation have not been considered in these. Lee and Tang (1997) consider a model where two products require $N$ sequential tasks for completion where inventory can be stored in a buffer after each task, with the buffer after the $N$ th task being finished goods. The first $k$ tasks are assumed to have been standardized, i.e., the inventory in the buffer after the $k$ th operation can be used for customization into either product. The tasks $k+1$ to $N$ are distinct for the two final products. Thus, the point of differentiation is right after the $k$ th step. Under a normal demand assumption for the two products and a discrete time setting, Lee and Tang (1997) consider the costs associated with standardizing any stage of task and develop interesting insights. Garg and Tang (1997) extend the analysis to a system with two points of differentiation: the family differentiation, and the product differentiation points.

The above papers assume that the production distribution process does not have any capacity constraints. Swaminathan and Tayur (1998) analyze a final assembly process with production capacity where inventory is stored in an intermediate form (vanilla boxes). In addition to the intermediate form, they allow the two extreme forms of vanilla boxes: as components, and as finished products. Therefore, this model captures both assemble to order (where components are stocked and products are assembled from the components after demand is realized) and make to stock (where inventory is carried in finished form only) as special cases. This approach allows for multiple points of differentiation, as there is no restriction on the type of vanilla box stored. The final product demands are assumed to have any stochastic distribution allowing for correlation across product demands. Swaminathan and Tayur (1998) assume that the vanilla box inventory follows a base stock policy. The inventory is brought up to that level in every period, and when demand is realized, products are assembled from vanilla boxes by adding other components within the production capacity. Unsatisfied demand is lost with a penalty and the remaining inventory of vanilla boxes incurs 
holding cost. Using a stochastic integer program and an efficient simulation-based algorithm, Swaminathan and Tayur (1998) explore the benefits of postponement through vanilla boxes under various settings. Among other results, they show that postponement using vanilla boxes outperforms both assemble-toorder and make-to-stock systems when the assembly capacity available is neither too slack nor too tight (representative of most real environments). Further, they find that the vanilla box approach is extremely powerful under high variance and negative correlation among product demands. Finally, they provide examples where stocking two types of vanilla boxes may be sufficient for a product family with 10 products, and the performance may be better than a make-to-stock approach (with all 10 products). Several other authors since have studied the postponement and the make-to-order versus make-tostock problem under various conditions (see Graman and Magazine 2002, Benjaafar and Gupta 2000).

Rajagopalan (2002) studies a multiitem problem with setup times between production, limited capacity, and congestion effects. In such an environment, making an item to order reduces inventory but may increase the lot size and inventory costs for other items that are made to stock. Further, lead times increase due to congestion effects, which may lead to higher safety stocks for made-to-stock items and poor service for made-to-order items. Given this tradeoff, Rajagopalan (2002) develops a nonlinear integer optimization model to determine which products should be make to order and which should be make to stock to minimize the total costs, and develops an efficient heuristic for the problem. More recently, Cattani et al. (2002a), motivated by customization and capacity issues faced by Timbuk2, develop a two-stage framework involving marketing and operations models to determine the conditions under which a firm benefits from using flexible capacity to produce custom products as demanded each period, and then filling the production schedule with make-to-stock output of standard products to restock inventory. This mitigates the "lumpy" demand for custom products, improving capacity utilization as compared to a focused approach where standard items are made with efficient capacity and custom products with flexible capacity. Cattani et al. (2002a) explore how capacity decisions impact demand parameters, and pricing impacts capacity decisions and, ultimately, production cost. The authors provide conditions under which convergence of the two models is achieved, and illustrate their framework with data from the messenger bag manufacturer.

Clearly, enabling customization in the product line is a great challenge to firms. Although the Internet facilitates a business model around customization, Zipkin (2001) describes the limits of mass customization. Swaminathan (2001b) presents a managerial framework based on standardizing operations that could potentially mitigate the negative effects of customization.

\section{Decision Technology}

One of the biggest impacts of the Internet on supply chain practices has been the development of different types of decision technologies, which can be used in supply chain planning and execution. This is also a result of the availability of accurate information that could increase the usefulness of decision models to a great extent. i2 (http://www.i2.com) and Manugistics (http://www.manugistics.com), two of the leading firms in the supply chain planning software industry, were the first to develop constraintbased planning approaches (linear and nonlinear programs) that tapped into data available in ERP systems to provide better supply chain planning and execution decisions as compared to earlier manufacturing resources planning (MRP) systems. With the growth in e-business, these and several other firms such as Agile, Inc. (http://www.agile.com) have developed more solutions that leverage the Internet to share information, and have created a suite of supply chain solutions. Academics in the supply chain area have also played an active role in creating newer decision technologies that use models developed in research, and have sufficiently adapted them to be used in practice (see Table 1).

Clearly, better decision technologies lead to better and more efficient decisions. However, the success of the implementation of decision technology depends, to a great extent, on how it is eventually used in 
Table 1 A Sample of Firms That Have Used Theoretical Advancements in Logistics and Supply Chain Management in Their Software Solutions

\begin{tabular}{|c|c|}
\hline Company & Description \\
\hline $\begin{array}{l}\text { Evant } \\
\text { (www.nonstop.com) }\end{array}$ & $\begin{array}{l}\text { Uses results from stochastic inventory theory } \\
\text { and daily forecasts to set inventory level } \\
\text { at the retail sites }\end{array}$ \\
\hline $\begin{array}{l}\text { Smart0ps } \\
\text { (www.smartops.com) }\end{array}$ & $\begin{array}{l}\text { Provides decision support for supply chain } \\
\text { planning (tactical and strategic) and } \\
\text { execution by tapping into real-time data and } \\
\text { using algorithms to determine supply chain } \\
\text { decisions, such as total chain inventory } \\
\text { levels, joint replenishment, and lot sizes }\end{array}$ \\
\hline $\begin{array}{r}\text { Manhattan Associates } \\
\text { (www.logistics.com) }\end{array}$ & $\begin{array}{l}\text { Provides a suite of tools that enables real-time } \\
\text { sharing of information about transportation } \\
\text { capacities and helps in reducing inefficiencies }\end{array}$ \\
\hline $\begin{array}{l}\text { AspenTech } \\
\text { (www.aspentech.com) }\end{array}$ & $\begin{array}{l}\text { Provides firms in the process industry with } \\
\text { real-time information and analytical and } \\
\text { simulation tools to optimize their most } \\
\text { important processes }\end{array}$ \\
\hline $\begin{array}{l}\text { 4R Systems } \\
\text { (www.4rsystems.com) }\end{array}$ & $\begin{array}{l}\text { Provides decision support to forecast and plan } \\
\text { for production and inventory management } \\
\text { more efficiently in the retail sector }\end{array}$ \\
\hline $\begin{array}{l}\text { Optiant, Inc. } \\
\text { (www.optiant.com) }\end{array}$ & $\begin{array}{l}\text { Provides software to help manufacturers } \\
\text { design and configure their supply chains } \\
\text { based on inventory and responsiveness } \\
\text { needs }\end{array}$ \\
\hline $\begin{array}{l}\text { LogicTools } \\
\text { (www.logic-tools.com) }\end{array}$ & $\begin{array}{l}\text { Provides optimization-based decision-support } \\
\text { tools for logistics and inventory management }\end{array}$ \\
\hline $\begin{array}{l}\text { MCA Solutions } \\
\text { (www.mcasolutions.com) }\end{array}$ & $\begin{array}{l}\text { Provides real-time information and decision } \\
\text { support for managing service parts inventory }\end{array}$ \\
\hline
\end{tabular}

the business process. Palmer and Markus (2000), through an empirical study, explore the interrelationship between business process change (in the context of quick response in the retail industry), degree of new information technology, and firm performance.

Decision technologies based on real-time agents for supply chain management that use optimization theory, agent behavior, and economic theory may become important in the future. Wellman (1993) considers a market-oriented programming approach to distributed problem solving by deriving the activities and resource allocations for a set of computational agents. He considers the multicommodity flow problem and shows that careful construction of the decision process, according to economic principles, can lead to efficient distributed resource allocation, and that the behavior of the system can be meaningfully analyzed in economic terms. Swaminathan et al.
(1998) propose the concept of intelligent agents in the supply chain that may have local and global information about the world around them and take appropriate actions (using decision models), depending on the situation. They provide a framework of agents and decision rules. With the Internet, it is possible to create such software agents that may be able to tap into required information from other agents and entities in the supply chain. More recently, Fan et al. (2003) discuss the design principle of a decentralized supply chain organization that uses the auction market as the coordinating mechanism. They present a bundle-trading market that can auction multiple resources in bundles. They show that such a system could provide the right incentive for all the participants to act in the best interest of the supply chain. This will take supply chain decision technology to the next level where distributed decision making may become more prevalent.

\section{Concluding Remarks}

In this paper, we have provided an overview of relevant analytical models in the area of e-business and supply chain management. The topic is broad, so we restricted our attention to areas in the supply chain, which have been significantly impacted by the advent of the Internet. We concentrated our efforts on a few papers that, in our opinion, have addressed important issues. Our focus has mainly been on research in operations management, operations research, and management science. We recognize that papers in marketing, information systems, economics, and other areas address other important issues related to electronic supply chains.

As firms strive to adapt their supply chains to the e-business environment, they need to decide how much and in what sequence they will be investing in various supply chain efforts to leverage the benefits of the new technology. Traditional models have focused on finding the optimal strategy for a single parameter (such as inventory, forecast, lead time, capacity, price). However, there is a growing need for models that can provide insights into the relative impact of altering the different parameters in the supply chain. For example, a firm with limited resources 
may need to know whether it is better to invest in vendor-managed inventory or reduce the lead time with existing suppliers. Similarly, research that helps firms identify supply chain changes that have quick benefits versus longer term results will be in demand.

As more and more firms begin to integrate their online and traditional operations and share more information over the Internet, real-time supply chain management models on product life-cycle management, dynamic pricing and production coordination, integrated models for supply consortia, and the coordination of Internet and traditional channels, are going to become all the more significant.

\section{Acknowledgments}

The authors thank the editors, an anonymous associate editor, and four anonymous referees who provided valuable input and comments that have contributed to improving the content and exposition of this paper.

\section{References}

Anupindi, R., Y. Bassok. 1999. Centralization of stocks: Retailers versus manufacturers. Management Sci. 45(2) 178-191.

,$- \ldots$, E. Zemel. 2001. A framework for analysis of decentralized distribution systems with implications for e-commerce. Manufacturing Service Oper. Management 3(4) 349-368.

Arntzen, B., G. Brown, T. Harrison, L. Trafton. 1995. Global supply chain management at DEC. Interfaces 25(1) 69-94.

Aviv, Y. 2001. The effect of collaborative forecasting on supply chain performance. Management Sci. 47(10) 1326-1343.

Balasubramanian, S. 1999. Mail vs. mall: A strategic analysis of competition between direct marketers and conventional retailers. Marketing Sci. 17(3) 181-195.

Benjaafar, S., D. Gupta. 2000. Make-to-order, make-to-stock or delay product differentiation?-A common framework for modeling and analysis. Working paper, Department of Mechanical Engineering, University of Minnesota, Minneapolis, MN.

Bramel, J., D. Simchi-Levi. 1997. The Logic of Logistics. SpringerVerlag, New York.

Brynjolfsson, E., M. D. Smith. 2000. Frictionless commerce? A comparison of Internet and conventional retailers. Management Sci. 46(4) 563-585.

Butler, P., T. W. Hall, A. M. Hana, L. Mendonca, B. Augustine, J. Manylika, A. Sahay. 1997. A revolution in interaction. McKinsey Quart. 15-23.

Bylinski, G. 2001. The e-factory catches on. Fortune (July 23).

Cachon, G. 2003. Supply chain coordination with contracts. S. Graves, T. de Kok, eds. Supply Chain ManagementHandbook in OR/MS, Vol. 11. North-Holland, Amsterdam, The Netherlands.
_ M. Lariviere. 2001. Contracting to assure supply: How to share demand forecasts in a supply chain. Management Sci. 47(5) 629-646.

Cattani, K., W. Hausman. 2000. Why are forecast updates often disappointing? Manufacturing Service Oper. Management 2(2) 119-127.

, G. Souza. 2002. Inventory rationing and shipment flexibility alternatives for direct market firms. Production Oper. Management 11(4) 441-457.

—, E. Dahan, G. Schmidt. 2002a. Spackling: Smoothing maketo-order production of custom products with make-tostock production of standard items. Working paper, KenanFlagler Business School, University of North Carolina, Chapel Hill, NC.

_ , W. Gilland, J. M. Swaminathan. 2002b. Coordinated pricing on traditional and Internet channels. Working paper, KenanFlagler Business School, University of North Carolina, Chapel Hill, NC.

Celikbas, M., J. G. Shanthikumar, J. M. Swaminathan. 1999. Coordinating production quantities and demand forecasts through penalty schemes. IIE Trans. 31(3) 851-864.

Cetinkaya, S., C. Y. Lee. 2000. Stock replenishment and shipment scheduling for vendor managed inventory. Management Sci. 46(2) 217-232.

Chan, L., D. Simchi-Levi, J. Swann. 2001. Dynamic pricing for manufacturing with stochastic demand and discretionary sales. Working paper, Massachusetts Institute of Technology, Cambridge, MA. http://www.isye.gatech.edu/ jswann/publications/SwannManuDynPricing.pdf.

Chen, F. 1999. Decentralized supply chains subject to information delays. Management Sci. 45(8) 1076-1090.

, Z. Dresner, J. K. Ryan, D. Simchi-Levi. 2000. Quantifying the bullwhip effect in a simple supply chain: The impact of forecasting lead time and information. Management Sci. 46(3) 436-443.

Cheung, K. L., H. L. Lee. 2002. The inventory benefit of shipment coordination and stock rebalancing in a supply chain. Management Sci. 48(2) 300-306.

Clark, A., H. Scarf. 1960. Optimal policies for a multi-echelon inventory problem. Management Sci. 6 475-490.

Davenport, A. J., J. R. Kalagnanam. 2001. Price negotiations for procurement of direct inputs. B. Dietrich, R. Vohra, eds. Mathematics of the Internet: Auctions and Markets. Springer-Verlag, New York.

Dong, L., E. Durbin. 2001. Markets for surplus components with a strategic supplier. Working paper, Olin School of Business, Washington University, St. Louis, MO. http://www.olin.wustl.edu/ faculty/durbin/Papers/DongDurbinSurplusMarketMS.pdf.

Druehl, C., E. Porteus. 2001. Price competition between an Internet firm and a bricks and mortar firm. Working paper, Graduate School of Business, Stanford University, Stanford, CA.

Elmaghraby, W. J. 2000. Supply contract competition and sourcing policies. Manufacturing Service Oper. Management 2(4) 350-371. 
Eppen, G., L. Schrage. 1981. Centralized ordering policies in a multi-warehouse system with lead times and random demand. L. B. Schwartz, ed. Multi-Level Production Inventory Control Systems: Theory and Practice. North-Holland, Amsterdam, The Netherlands, 51-58.

Erhun, F., P. Keskinokak, S. Tayur. 2001. Sequential procurement in a capacitated supply chain facing uncertain demand. Working paper, Graduate School of Industrial Administration, Carnegie Mellon University, Pittsburgh, PA. http://www.gsia.cmu.edu/ andrew/stayur/feryal.ps.

Fan, M., J. Stallaert, A. B. Whinston. 2003. Decentralized mechanism design for supply chain organizations using an auction market. Inform. Systems Res. 14(1) 1-22.

Fisher, M. L., J. H. Hammond, W. R. Obermeyer, A. Raman. 1994. Making supply meet demand in an uncertain world. Harvard Bus. Rev. 72(3) 83-92.

Gallien, J., L. Wein. 2000. Design and analysis of a smart market for industrial procurement. Working paper, Massachusetts Institute of Technology, Cambridge, MA. http://web.mit.edu/ lwein/www/smarket.pdf.

Garg, A., C. S. Tang. 1997. On postponement strategies for product families with multiple points of differentiation. IIE Trans. 29 641-650.

Gavirneni, S., R. Kapuscinski, S. Tayur. 1999. Value of information in capacitated supply chains. Management Sci. 45 16-24.

Geoffrion, A., G. W. Graves. 1974. Multicommodity distribution system design using benders decomposition. Management Sci. 20(5) 822-826.

—, R. Krishnan. 2001. Prospects for operations research in the e-business era. Interfaces 31(2) 6-36.

Graman, G. A., M. J. Magazine. 2002. A numerical analysis of capacitated postponement. Production Oper. Management 11(3) 340-357.

Granot, D., G. Sosic. 2001. Formation of alliances in Internet-based supply exchanges. Oper. Res. Forthcoming.

Graves, S. C., A. G. de Kok. 2003. Supply Chain ManagementHandbook of OR/MS. North-Holland, Amsterdam, The Netherlands. Forthcoming.

—, R. Kan, P. H. Zipkin. 1993. Logistics of Production and Inventory-Handbook of OR/MS. North-Holland, Amsterdam, The Netherlands.

Huang, W., J. M. Swaminathan. 2003. Pricing in mixed channels: Analysis and bounds. Working paper, Kenan-Flagler Business School, University of North Carolina, Chapel Hill, NC.

Jin, M., S. D. Wu. 2001a. Supply chain coordination in electronic markets: Auction and contracting mechanisms. Working paper, Lehigh University, Lehigh, PA, http://www.lehigh.edu/ sdw1/ jin1.pdf.

- $-2001 \mathrm{~b}$. Supply chain coalitions in e-commerce auctions: Validity requirements and profit distribution. Working paper, Lehigh University, Lehigh, PA, http://www.lehigh.edu/ sdw1/jin2.pdf.

Johnson, C., K. Delhagen, A. Dash. 2002. US e-commerce: The next five years. Forrester Report (August 27).
Kaminsky, P., J. M. Swaminathan. 2001. Utilizing forecast band refinement for capacitated production planning. Manufacturing Service Oper. Management 3(1) 68-81.

Keenan, F., S. Ante. 2002. The new teamwork. Bus. Week (February 18).

Keskinocak, P., S. Tayur. 2001. Quantitative analysis of Internet enabled supply chains. Interfaces 31(2) 70-89.

Kleindorfer, P., D. J. Wu. 2003. Integrating long-term and short-term contracting via business-to-business exchanges for capitalintensive industries. Management Sci. 49(11) Forthcoming.

Lee, H. L. 1996. Effective management of inventory and service through product and process redesign. Oper. Res. 44 151-159.

, C. Billington. 1992. Managing supply chain inventories: Pitfalls and opportunities. Sloan Management Rev. 33(3) 65-77.

_ 1 . 1993. Materials management in decentralized supply chains. Oper. Res. 41(5) 835-847.

, R. So, C. S. Tang. 2000. The value of information in a twolevel supply chain. Management Sci. 46(5) 626-643. C. S. Tang. 1997. Modeling the costs and benefits of delayed product differentiation. Management Sci. 43(1) 40-53.

, S. Whang. 1998. Value of postponement from variability reduction through uncertainty resolution and forecast improvement. T. Ho, C. Tang, eds. Product Variety Management: Research Advances. Kluwer Publishers, Boston, MA, 66-84.

_ 2 2002. The impact of secondary market on the supply chain. Management Sci. 48(6) 719-731.

_ V. Padmanabhan, S. Whang. 1997. Information distortion in the supply chain: The bullwhip effect. Management Sci. 43(4) 546-558.

Lundegaard, K. 2001. Bumpy ride: Supply chain management sounds beautiful in theory; in real life, its a daunting task. Wall Street J. (May 21).

Miyoaka, J., W. Hausman. 2001. Why use stale forecasts? Because sometime they perform better! INFORMS Annual Meeting, Miami, FL.

Nault, B. R., R. K. Tyagi. 2001. Implementable mechanisms to coordinate horizontal alliances. Management Sci. 47(6) 787-799.

Netessine, S., N. Rudi. 2001. Supply chain structures on the Internet: Marketing operations coordination. Working paper, Wharton School, University of Pennsylvania, Philadelphia, PA, http: //omg.simon.rochester.edu /omgHome /Rudi /Serguei / dropship.pdf.

Palmer, J. W., M. L. Markus. 2000. The performance impacts of quick response and strategic alignment in specialty retailing. Inform. Systems Res. 11(3) 241-259.

Peleg, B., H. L. Lee, W. H. Hausman. 2002. Short term e-procurement strategies versus long term contracts. Production Oper. Management 11(4) 458-479.

Rajagopalan, S. 2002. Make-to-order or make-to-stock: Model and application. Management Sci. 48(2) 241-256.

Reinhardt, A. 2001. Tesco bets small and wins big. Bus. Week (October 1).

Seifert, R., U. Thonemann, S. Rockhold. 2001. Integrating direct and indirect sales channels under decentralized decision making. Working paper, IMD, International, Lausanne, Switzerland. 
SWAMINATHAN AND TAYUR

Models for Supply Chains in E-Business

Simchi-Levi, D., D. Wu, Z. Shen. 2003. Supply Chain Analysis in the eBusiness Era. Kluwer Publishing. Forthcoming.

Sodhi, M. 2001. Applications and opportunities for operations research in Internet enabled supply chains and electronic martketplaces. Interfaces 31(2) 56-69.

Swaminathan, J. M. 2001a. Supply chain management. International Encyclopedia of the Social and Behavioral Sciences. Elsevier Sciences, Oxford, England.

2001b. Enabling customization using standardized operations. California Management Rev. 43(3) 125-135.

, H. L. Lee. 2003. Design for postponement. S. Graves, T. de Kok, eds. Supply Chain Management-Handbook in OR/MS, Vol. 11. North-Holland, Amsterdam, The Netherlands, 199-226.

_ , S. R. Tayur. 1998. Managing broader product lines through delayed differentiation using vanilla boxes. Management Sci. 44 161-172.
_ 2003. Tactical planning models for supply chain management. S. Graves, T. de Kok, eds. Supply Chain ManagementHandbook in OR/MS, Vol. 11. North-Holland, Amsterdam, The Netherlands, 423-454.

_ S. F. Smith, N. Sadeh. 1998. Modeling supply chain dynamics: A multi-agent approach. Decision Sci. 29(3) 607-632.

Tayur, S. R., R. Ganeshan, M. Magazine. 1999. Quantitative Models in Supply Chain Management. Kluwer Publishers, Boston, MA.

Venkatesh, S., J. M. Swaminathan. 2003. Managing product variety through postponement: Concept and applications. C. Billington, T. Harrison, H. L. Lee, J. Neale, eds. The Practice of Supply Chain Management. Kluwer Publishing, Boston, MA, 139-155.

Wellman, M. P. 1993. A market-oriented programming environment and its application to distributed multicommodity flow problems. J. Artificial Intelligence 1 1-23.

Zipkin, P. 2001. The limits of mass customization. Sloan Management Rev. 42(3) 81-87.

Accepted by Arthur M. Geoffrion and Ramayya Krishnan; received January 2002. This paper was with the authors 17 months for 5 revisions. 